\title{
Patients' rights in England and the United States of America: The Patient's Charter and the New Jersey Patient Bill of Rights: a comparison
}

\author{
Melanie H Wilson Silver Shore Memorial Hospital, New fersey, USA and the University of Manchester, England
}

\section{Abstract}

The Patient's Charter has been in effect for nearly five years. This article considers the purpose and value of the document through a comparison with the New fersey Patient Bill of Rights. Patient rights statements have been posted in American hospitals for more than twenty years. However, the New fersey document and the patient rights programme it established seven years ago, have proven to be economically effective, successful in their representation of patients and enforceable, due to the adoption of state legislation and regulation to oversee the process. Several examples of how the programme works are included in the comparison, with a similar review of The Patient's Charter.

In the comparison the author argues that for the programme to succeed as it has done in New Fersey, the government will need to develop legislative backing to ensure enforcement, and an efficient system for monitoring compliance. The programme will need to become credible in the eyes of the health service user. The author suggests this may be best achieved by developing an efficient, accessible and user-friendly means of redress, should the patient consider his or her rights have been violated.

$A$ "mish-mash" of quality assurance standards and levels of care which patients can "expect" from the health service providers only serves to distract the health service user from the government's failure to commit the resources that would empower the patients rights portion of The Patient's Charter.

\section{Introduction}

Since the early 1970s many hospitals in New Jersey have voluntarily adopted, as policy, various versions of the Patient Bill of Rights. It was not until 1989, however, that laws were enacted by the New Jersey legislature declaring that, as a matter of public policy, acute care hospital patients had certain specific rights. The law also provided for a mechanism to

\section{Key words}

Health care; patients' rights (UK, USA); Patient's Charter; legislative protection; regulatory enforcement. enforce those rights. The newly passed bill and the administrative regulations that were promulgated under its authority came to be known as the New Jersey Patient Bill of Rights. ${ }^{1}$

With the protection of legislation, the provisions of the regulation were designed to be overseen by a body external to the health system itself, in this case the New Jersey State Department of Health and Senior Services. By way of explanation, the State Department of Health and Senior Services is not integrated with the structure of the various hospitals and health care systems in the state. It is an administrative agency, part of the executive branch of government, charged with, among other things the licensing and regulation of acute care hospitals in the state.

Hospitals and health care providers in New Jersey are mainly private, for profit or not-for-profit entities, with large county facilities having been phased out. The majority of hospitals are self-governing, but are tied to state and federal regulation through the Medicare and Medicaid reimbursement they receive. ${ }^{2}$ Therefore, while the state is the regulatory overseeing body, the hospitals and health care systems in New Jersey are not part of a state-run health care system, as they are in England. ${ }^{3}$

In England, within the last five years the government introduced a document entitled The Patient's Charter. The charter mentions a limited number of patients' rights, but unlike its American counterpart is neither enforced by statute, externally regulated nor, as yet, monitored in any official way. ${ }^{4}$

At this early stage it is worth briefly raising a patientrights-based approach to the discussion of these two documents, in particular, in relation to the evolution in the system from health care to maintain a healthy community, in a collective sense, to health care to maintain the individual. This position, which might be termed the "patient-rights-based justification" is worthwhile considering. It represents a logical evolution from the community-based health care delivery system in the early decades of the National Health Service, to the more individually focused health care delivery system of the later part of this century.

It is possible to compare the growth of consumerism in the 1960s in the United States, and the subsequent 
emergence of the civil rights movement, with the increasing public awareness in England of the changes in the National Health Service. This is particularly the case when changes are made with little, or next to no consumer involvement. It is relevant that there has been a change in the style of government over the last few decades. Less common in the 1990 s is the paternalistic, closed style of government that was present during the early years of the National Health Service. The recognition that open government promotes greater public knowledge, and one hopes, greater and sincere opportunity for public involvement in proposed changes in the health care system is relevant here. This may occur both as an individual or collective process.

Until the 1980s, the consumer response to the changes in health care was collective in nature, not unlike the communal delivery of health care itself. However, since the Thatcher government of the 1980 s and the Major government that followed, selfsufficiency and personal responsibility for one's health care needs and consumption have become the mantra of government. The current decade has seen the logical extension of health care consumerism, mirroring the evolution of individual management responsibility and accountability within the National Health Service itself. ${ }^{5}$

Finally, it should not be presumed that the system is either purely one of collective, communally delivered health care, or purely a more individual model. The system involves a mixture of both in varying proportions. For example, the national education programme expounding the benefits of a low-fat, high-fibre diet has been made widely available as a way by which community health may be improved. It is, however, the responsibility of the individual to espouse the healthy diet and lifestyle and, it is hoped, thereby improve his own health. Enough individuals accepting responsibility in this way should, in theory, result in a healthier community as a whole.

The ethical concerns raised in the "just" delivery and distribution of health care to those concerned with their individual needs, rather that the greater welfare of the community, does begin to rear its head at this point. Clearly a self-care-motivated health system has the potential to impinge upon the "just" distribution of health care resources. However, selfcare should not be confused with selfish behaviour, and the former should be explored carefully because there is great value in individuals accepting personal responsibility for maintaining their own good health.

The purpose of this article is to analyse a model of patient rights' regulation that has been operating successfully outside England, and to use it as an example to promote positive change. Although there are many differences between the health care systems of America and England, there are valuable lessons to be learned by reviewing the New Jersey example, and its regulatory standards. ${ }^{6}$ The primary concern is that in its current format, The Patient $\frac{\mathbb{2}}{\mathrm{S}}$ Charter is without significant independent regulation and legislative protection. As a result, the charter i⿸ largely ineffective to the health service user.

It will be argued in this article that if the govern $\stackrel{=}{=}$ ment is committed enough to develop a charter witk the presumed purpose of improving the patient's expe흘. rience of the health service, at the same time address $\frac{\overline{\bar{c}}}{\frac{}{\circ}}$ ing patient rights, yet not committed enough to put ir place the appropriate protective legislation, then this is a waste of both time and resources. It appears that the government has not proceeded in this way, for fear of extra cost, and expected demands on those chosen t $\sigma_{\omega}$ regulate the system, whoever they may be?

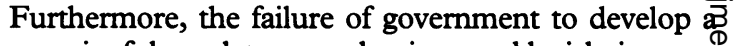
meaningful regulatory mechanism, and legislative proiv tection for the rights of health service users, may suggest that the government is not truly committed to the programme. At present, the government is taking $\overrightarrow{z_{0}}$ position which amounts to little more than lip-service? assuming that it was the government's intention to make a positive change in the first place.

This article provides a detailed comparative revievo of the English Patient's Charter and the New Jerseys Patient Bill of Rights. Following a general comparison $\overrightarrow{20}$ there will be a more detailed discussion, includinge several examples of what makes these documents similar in certain ways and very different in otherșo The conclusion recommends that The Patient's Chaferes be extended, focusing on advocacy for, and enforce ment of, the rights of National Health Service users $\frac{0}{D}$

\section{Historical development}

In 1991, with much pomp and circumstance the British government launched the citizen's charter initiative in the National Health Service, The Patient 5 Charter. This was a widely distributed booklet, con $\bar{D}$ taining a series of ten "rights" which referred to the patient's entitlement to care in the National Health Service. In addition to the ten Patient's Charters "rights", were two other categories of standards. The first was National Charter Standards which contained $P$ nine statements that expressed the standards of servic a patient obtaining care anywhere in the NationaFHealth Service could expect to receive. The second was a series of five statements entitled "Local Charter Standards". These set forth service standards than local health care providers would be expected to reach ${ }_{\sigma}^{\omega}$ or exceed. This second set of standards related for example, to waiting times for "elective procedures" and outpatient appointments.

This was the first document since the inception of the National Health Service in 1948 which stated the rights of patients in England, however limited. The्D charter stated those "rights" as pre-existing, and a? the same time expanded the number of the patient's?
rights from seven to ten.

In 1973, some twenty years prior to the publication of The Patient's Charter in England, the 
American Hospital Association published the first document in America to express the rights of patients while in hospital. The American Hospital Association Patient Bill of Rights originally contained thirteen listed rights, and became a widely used model for American hospitals. The American Hospital Association's Patient Bill of Rights was used to express what all patients should expect in hospital, while at the same time providing a tangible means by which hospitals could express their commitment to their patients. The document had a strong influence on hospitals throughout America, and ultimately, influenced many states to develop their own distinctive patient rights bills.

\section{Contrast of content}

In the United States federal legislation exists in the area of patient rights. However, it is largely concerned with matters of confidentiality, patient selfdetermination, discrimination and disability. In contrast, the more mundane routine circumstances concerning the rights of patients have fallen to the individual states to legislate and regulate.

In the late 1980s the State of New Jersey passed its version of the patient bill of rights. With time it has expanded somewhat in content but remains substantively unchanged. At present, the regulations of the New Jersey State Department of Health and Senior Services contain thirty separate paragraphs of patient rights regulations. The regulations cover many different aspects of a hospital in-patient stay. The content appears as a simply stated list of rights, either in the form of the administrative code in its entirety, or the licensed summary format. The New Jersey Patient Bill of Rights includes both a list of the individual rights, and information expanding and explaining each right stated in the document.

The rights include, but are not limited to: the right to access to care; the right to be free from discrimination; the right to be introduced to any health care provider by name in addition to the use of name badges; the right to receive confidential treatment; the right to and the procedure for, obtaining a copy of medical records; the right to provide informed consent; the right to refuse medical care with the knowledge of the consequences; the right to decline participation in medical research or with medical or health care students; the right to be informed of the facility's policies and procedures regarding the withdrawal and withholding of life support; the right to be informed of the right to transfer care from a practitioner or facility, and the procedure to accomplish it.

Other rights relate to being provided with appropriate medical follow-up and nursing support upon discharge, and the discharge appeals procedure; the right to receive a copy of the hospital's billing rates and an itemised bill, and the right to be provided with assistance with application for health insurance payment, public assistance and charity care. Even without listing all the rights covered, it is apparent that there are significant differences between the scope of these two documents.

The Patient's Charter contains a list of the sonamed "rights" extended to every patient using the National Health Service. These consist of the right to receive health care based on medical need and no other factor; the right to be registered with a general practitioner, and to be able to change GP without difficulty; the right to emergency treatment; the right to a second opinion under certain circumstances, and the right to provide an informed consent, although there is no mention of a right to refuse medication or treatment, even though this is implicit in the concept of informed consent. There is a right of access to one's health record and an assurance that staff will keep those records confidential, and finally there is the right to decline to participate in medical research and medical training. This final right regarding medical research may be grounded more in the desire to comply with the Declaration of Helsinki, which specifies guidelines on medical research involving human subjects, than in a commitment to strengthen the rights of individual patients per se.

While at times difficult to follow, The Patient's Charter does specify, towards its conclusion, how to complain, and who to contact within the National Health Service to do so. Nowhere in the charter however, is it stated how a person can complain directly to the health care provider at the time of treatment, if he/she believes that the listed rights have been violated. It seems that these rights are not currently protected by law, regulated or empowered by government. While an efficient and effective complaint management mechanism is clearly desirable, it is no substitute for statutorily protected rights coupled with enforcement and monitoring procedures, external to the health care provider, relative to alleged rights violations. Moreover, to be truly effective there must be consequences for those who violate patient rights, possibly through a system of sanctions and fines. It may be necessary to develop a deterrent to be utilised where patients' rights violations recur.

Interestingly the system of regulation in New Jersey is not the one originally proposed in the legislation. As initially proposed in the state legislature, the Patient Bill of Rights would have established a private cause of action, enforceable against a hospital through a civil suit, for anyone whose specified rights had been violated. In such a case, a patient who claimed that his rights had been, or were being, violated by a hospital could seek redress through the civil court system. It was presumed that the patient would be seeking compensatory and, in an appropriate case, punitive, damages. Consequently, the "enforcement mechanism" was originally envisaged to be the potential civil liability, in addition to enforcement through a state department of health review and, where warranted, corrective action. ${ }^{7}$ 
As ultimately adopted, the bill provided for enforcement exclusively by the State Department of Health and Senior Services, and did not establish a private cause of action for individuals who believed they had suffered a patient rights violation. Therefore, it is clear that the law, as enacted, was not intended to create rights that are enforceable by individual health care consumers.

One might speculate as to the reasons why a decision was made to expel the patient from the regulatory process. Certainly even a decade ago, the burgeoning legal system could have done without the burden of added civil litigation. Perhaps it was the intention of the regulatory agency, the State Department of Health and Senior Services in this case, to limit the number of individual complaints to protect the genuine cases and exclude the "habitual complainers"!

The State Department of Health and Senior Services has seemed unable to offer the actual reasons for the decision, so the truth may never be known. In its defence, the Director of Licensing, Certification and Standards for the State Department of Health and Senior Services was able to provide the following information.

There are no statistics compiled by the state to reflect the total number of complaints regarding alleged patient rights violations made to the state department of health. However, all complaints are taken seriously and investigated. Of the ones that are found to be either partially substantiated or fully substantiated, only twelve cases in the last five years have resulted in a fine. The fines have ranged from $\$ 250-\$ 2,000$, and the levels are broadly guided by the state enforcement regulations, although the director and his team have some discretion in each case. $^{8}$

Since 1988 hospitals have paid the fines levied without resorting to the appeal process, which would require the facility to retain counsel and attend an administrative law hearing. Three factors have contributed towards persuading health care facilities to pay up in such cases: the high cost of a legal defence, the fear of future licensure implications, and the fear that failure to pay up is likely to add to the cost of business insurance. In other areas of state regulation, a similar appeals process is usually pursued only if it is considered necessary as a part of a malpractice defence, or if it is likely to add considerably to the cost of insurance coverage in the future, thus threatening the economic security of the entity involved.

It should be noted that in New Jersey, at this time, there have not been any legal cases or opinions resulting from an alleged patient rights violation. The majority of litigation is to do with medical malpractice and, therefore, is not relevant to these issues.

In the case where a complaint received by the State Department of Health and Senior Services is found to be substantiated, but is thought not sufficiently serious to warrant the imposition of $a \varrho$ fine, the health care facility may be required to submit a "plan of corrective action" in a given period of time. The State Department of Health and Senior? Services will review this plan of action for compli- $\overrightarrow{\vec{s}}$ ance, either on an unannounced visit or during ano annual state re-licensure survey, when any non-com-등 pliance will be addressed.

Some complaints rise neither to the level of cor- $\frac{\Phi}{0}$ rective action plans nor fines, and in these cases the facility will most often be issued with a stiff warning. Should the violation occur again, the punishment. will not be so light. There are no statistics available $\overrightarrow{\vec{H}}$ to demonstrate the number of either type of these cases, although the Director of Licensing, $\overrightarrow{\bar{B}}$ Certification and Standards advises that thankfully the level of complaints overall is low..$^{9}$

As a final comment in the area of sanctions, the State Department of Health and Senior Services has $\frac{\vec{\omega}}{\omega}$ the authority to close a hospital down or prevent ${ }_{0}$ admissions if it has been found that such circum-? stances warrant it. Such extreme cases are rare, and $\overrightarrow{>}$ occur only if the State Department of Health and Senior Services believes that patients' lives are in immediate danger.

In England, until April of 1996 the system of redress involving the hospital or trust chief office्f., the family health service or health authority and ul mately, in certain select circumstances the Nation Health Service Ombudsman, was limited, confusing and slow. It is yet to be seen if the newly adopted\%을 complaints procedure, based on the review and rec- $\varrho$ ommendation of The Wilson Committee has $\overrightarrow{\vec{\sigma}}$ overcome the weaknesses of the old complaint 3 system. ${ }^{10}$ It is hoped that the new system will be satisfactory, and of benefit to patients and theiro families.

Until recently, if a system of recourse existed in the National Health Service and outside the courtroom, then it was a very well kept secret. Indeed, the way thematter has been handled in the USA mayo be one of the few instances where the Americans have succeeded in keeping out of the courtroom, so far! 을

On a local level, the New Jersey Patient Bill of Rights contains a reference to a complaints procedure which requires the listing of a named person responsible for complaint management, in each indi-vidual facility. This responsibility usually falls within the scope of the patient representative or advocate. $\omega$ As with all patient rights criteria, the information as to who is responsible for complaint management iso provided upon admission to patients and family members, in addition to it being posted in every in-patient room, and in all public areas. Apart from the internally developed complaint management system, $\frac{\overrightarrow{\mathrm{C}}}{\mathrm{D}}$ the Patient Bill of Rights lists the freephone number? of a twenty-four hour "complaint hot-line", for com- $\triangle$ plaints to the State Department of Health and Senior Services. This information is also conspicuously displayed in various locations within the 
facility, and made available in the ways that have already been mentioned. It is curious that the issue of the patient's right to complain is detailed only in a single paragraph of the New Jersey Administrative Code. The subject of the right to complain and the appropriate avenues to follow comprise only a small part of the entire New Jersey document.

The New Jersey Patient Bill of Rights fulfils certain criteria lacking in The Patient's Charter, as drafted currently. The bill of rights is designed as a public declaration of the rights of any person admitted to any hospital. The statute which empowers the administrative code specifies the individual provisions in each regulation. The document covers a wide range of eventualities from the right to have access to one's medical record, to the right to be provided with an interpreter if one speaks a foreign language. The bill does not, however, purely dictate demands and acceptable standards to the health care providers.

The New Jersey State Department of Health and Senior Services will assist hospitals by stating that a service must be provided as soon as possible, or within a reasonable time period. The state will also determine reasonable copying charges, and inform patients and hospitals how much can be charged for photocopies of test results and medical records. In many cases, the State Department of Health and Senior Services requires that individual hospitals determine their own standards of time for compliance with state regulations. This can be helpful if a realistic time frame is set. However, if a health care facility fails to meet its own standard, it can also be sanctioned for failing to adhere to its own internal policy. There is no official publication of league performance tables in New Jersey, and the benchmarking that is done relates to in-patient satisfaction survey results. This work is carried out quite separately from the area of patient rights, and is usually part of the hospital's continuous quality improvement process. Patient satisfaction surveys are carried out in compliance with the federal government requirements, and are monitored through the Joint Commission on Accreditation of Health Care Organisations.

In the New Jersey Patient Bill of Rights there is no mention of charter standards, either individually or as a state-wide system, and in this respect The Patient's Charter exceeds the New Jersey Patient Bill of Rights as a tool of measuring quality nationally. Quite simply, the New Jersey document never set out to be anything other than a statement of patient rights. In contrast The Patient's Charter includes a statement of rights, the use of the word "bill" being inappropriate at this point, since currently no such bill exists in England.

\section{Case examples}

It can be argued that by publishing a "mish-mash" of standards and rights, the British government appears to be emulating the American model in a half-hearted way. This then begs the question why that government would be inhibited from committing fully to a cause as significant as this, which appears (at least to the health care consumer), as a basic human right.

At the same time, a significant contrast between the American bill and the English charter can be seen. Whereas these issues are identified as "rights" in the American document, in the English charter they seem to be expressed as standards expected to be adhered to. An example of this is the National Charter Standard that deals with the fact that a patient can expect the National Health Service ". . . to respect [your] privacy, dignity and religious and cultural beliefs ..."." In contrast the American document plainly states the right ". . . to be treated with courtesy, consideration and respect for the patient's dignity and individuality". ${ }^{12}$ This right is expressed again in paragraph twenty of the American document, which describes the right to privacy during medical treatment and for personal hygiene functions.

In the absence of research in this area, anecdotal evidence suggests that compliance with the bill has not as yet proven to be prohibitively expensive or labour intensive. The majority of patient rights enforcement work is carried out by the hospital patient representative, who often works singlehandedly in the facility. When the State Department of Health and Senior Services investigates an alleged patient rights violation, they conduct their investigation independently of the hospital staff and the internal complaints procedure.

Had the costs of compliance proved to be uneconomical, the health care system in New Jersey might have ground to a halt or been thrown into financial disarray! Admittedly, there is an ongoing financial crisis within the American health care system, but it cannot be blamed solely on the cost of complying with the provisions in the patient bill of rights! On the contrary, it seems that the basic rights listed above appear to be too exacting for the British government to expect health service providers to attain. One would hope that this is not the case, and that perhaps it can be argued that the pressure on National Health Service personnel to comply with other aspects of The Patient's Charter, and for example, reduce out-patient waiting times, thereby improving their status on the national league tables, has diverted time and resources away from the basic and comparatively attainable aspects of care related to patient rights.

Compliance need not cost vast amounts of money, and innovative ways to maintain compliance are encouraged by the State Department of Health and Senior Services in New Jersey. One example of this can be found in paragraph five of the New Jersey document, which states that patients shall have the right:

"To receive, as soon as possible, the services of a 
translator or interpreter to facilitate communication between the patient and the hospital's health care personnel."13

In compliance with the above provision, many New Jersey hospitals contract with interpreting agencies, while others rely on using hospital employees to assist where a foreign language speaker is needed. However, the high cost of privately certified interpreter services, (a necessity when obtaining a valid informed consent), and the time delay until one can get to the hospital, may result in a failure to comply with the regulations in a timely manner. This may result in such services being more trouble than they are worth. Where alternatives are used, the ethical issues arising are many and complex. This is particularly the case when a member of non-professional staff is used to translate for a patient. The ethical concerns that arise range from the appropriateness of using a male member of staff for translation during a gynaecological examination, to the closeness of ethnic or cultural groups in the community, where a misunderstanding about a confidential matter could lead to a potentially damaging and costly breach of confidentiality for all parties concerned. Such is the risk of utilising non-professional staff in intimate situations in a misguided effort to economise. While the use of a family member is acceptable, this again requires attention to issues of accuracy in translation, patient confidentiality and respect for patient privacy, all of which must be taken into account.

For the last five years many of the hospitals in New Jersey have subscribed to a telephone interpreting service. Run by AT\&T, the "Language Line" can provide interpreters who are trained in medical terminology and issues of confidentiality, while being sensitive to the stresses of certain hospital and clinical situations. The service costs a significant one-time subscription fee, although this is considerably less than the cost of a fine for non-compliance. There is also a charge each time the service is used, based on the length of the call. The first step in using this service is to have the patient identify the language he/she speaks. This is done by presenting the patient with a "point talk" card which contains a statement in numerous languages that says in essence: "Point here if this is the language you speak, and tell me your name". Once the foreign language, dialect and patient's name have been identified a call to a freephone number, and ninety seconds will secure an interpreter in any one of the one hundred and forty languages offered in the service. During the call, which can be conducted as a conference call, or by using a double point telephone or speakerphone, the patient can be put at ease, and the necessary conversation and information exchange can take place. The service is extremely convenient as a call can be made and an interpreter accessed as soon as the need arises. It is a favourite with physicians as they are not kept waiting for a transla $\frac{\bar{\phi}}{2}$ tor while on rounds, and they are able to render appropriate care in a timely manner.

The State Department of Health and Senio Services has been so impressed with this service that: it recognises the use of "Language Line" as the standard, for compliance in this area. Beyond the requirement to provide interpreter services, state law requires that patient information, forms and docu $\frac{\bar{s}}{\frac{5}{5}}$ ments be translated into the predominant foreign languages, if the population using that language conew stitutes ten per cent or more of the population of the county where the hospital is situated. Many healthP care facilities provide patient educational material $\overrightarrow{\vec{\omega}}$ forms and information in foreign languages, regard. less of the foreign-speaking population level.

In England, as yet, there is no such standar\% service. While individual hospitals and trusts cerew tainly do provide translated written material, the standard is not uniform or assessable and is somewhat limited. A restricted telephone interpreteo service does operate in London, but is not in anyway as developed as in the United States.

It is perhaps ironic that a patient right that is affirmatively protected by law in England has been? omitted from The Patient's Charter. The right to refuse or decline a medical treatment or proceduree has historically been protected, and has traditionofly been enshrined in the Common Law right to provite a consent. While The Patient's Charter does incluses the right to refuse to be involved in medical research and to give an informed consent, it does not overtly: state that patients have the right to refuse the care that is offered to them. This is, in part, due to car $\vec{b}$ not being offered to patients, as it might be in the United States.

Health care delivery in England ascribes the responsibility to the general practitioner or consul tant, for informing the patient of the treatment choices available to him, or what treatment he is likely to receive. Such an exchange is based on the physician's superior medical knowledge and mas? occur for a number of reasons, individually or in combination with one another. Where the patiene trusts the physician's judgment, the patient may not value his own experience of the illness or conditionenough to bring it to the discussion. The physiciaro may not value the patient's viewpoint or experiench of illness, or see its relevance to his medical exper: tise; so it is not sought. As a result, the opportunity to be told that one need not agree to a prescribec treatment, is not as a rule offered to health service patients. In practical terms, in the majority of ciro cumstances, the ultimate decision-maker remains the physician.

The Patient Bill of Rights in New Jersey has separate provision for the right to refuse medicaf care. It is not to be confused with the regulation? that relate to obtaining an informed consent, or the right to not participate in medical research. Most 
significantly, it is stated that the patient has the right to:

“. . refuse medication and treatment after the possible consequences of this decision have been explained in language the patient understands. ..". ${ }^{14}$

As with the right to give an informed consent, the right to refuse treatment requires the patient to have the capacity to understand the consequences of his decision, even if it means that the patient is choosing to decline treatment which may result in his death. An addition, since the Quinlan case in 1976, there has been a long tradition of New Jersey case law which upholds the right of a patient to choose to have treatment withheld or withdrawn. ${ }^{15}$ This provision serves to support and strengthen the position of the patient in his right of refusal, and promotes the open discussion of these issues with the health care team.

\section{Conclusion}

Whilst the New Jersey health care system and its providers are not without fault, the New Jersey Patient Bill of Rights provides a strongly visible public commitment by all the parties concerned, towards the rights of the patients it serves. This, coupled with an accessible and enforceable mechanism of redress for patients who feel they may have been wronged, or had their rights violated, signifies that the strategy is working. The Patient Bill of Rights as it stands in New Jersey, currently expresses a strong universal commitment to the rights of all patients, and this has resulted in further advocating for individuals with special needs or challenges. For example, a deaf patient must be provided with the means to communicate, that he or she prefers. The hospital is therefore equipped to accept telephone calls from a teletype writer, known as a TTY. ${ }^{16}$ Hospital staff are trained to use a relay operator or TTY, as well as providing on-call sign language interpreters, TTY telephones in in-patient rooms, and point cards to identify patient needs.

At the same time the system is monitored and regulated in a manner that brings a reasonably high level of respect for, and satisfaction to, the patientuser and his relatives. The Patient Bill of Rights has become a programme that patients find desirable, and health care providers do not as a rule, attempt to short cut. The health care system in the state of New Jersey has accomplished an impressive balance between the level of patient-generated workload, the resources used and the cost to the health care facility, which is kept to a minimum.

There is a degree of disappointment in the limited impact of The Patient's Charter so far. The initiative is clearly in its early years, and must be given time to become seasoned and developed, as has its counterpart in New Jersey. However, the disproportionate emphasis placed on quality assurance in the guise of a commitment to patient rights, is a hollow gesture. The full benefit of the charter to all the users of the National Health Service will only be felt once the emphasis is placed on improving the patient experience through a programme of comprehensive, protected, enforceable patient rights.

The government is either severely confused, or relying on public ignorance.The public has, in fact, continued to tolerate the government's avoidance of the effort and the expense associated with developing the necessary patient rights programme. If The Patient's Charter is to be taken seriously as an honest effort to advocate for health service users, the current format will have to change. There is no benefit or satisfaction in asserting that patients have certain rights, while at the same time providing no enforceable follow-through or credible means of redress. Rather than placing a disproportionate amount of resources and importance on complaint management and issues of quality assurance, emphasising issues which are remote to the public unless they are affected by them, resources would be better spent on a programme like the one in New Jersey.

The transformation to "trust status" at some hospitals has provided a good opportunity to delegate the daily tasks that relate to patient rights to the facility, in the first instance. The growing group of patients' representatives in the National Health Service, should be involved in this process. Monitoring and compliance should, however, remain the responsibility of an empowered agency or quasi-autonomous entity, objectivity being a necessity. Now is the time to import one of the better innovations from the United States, mould the system to suit the cultural needs of the service users, and at the same time improve a health care system which has always been the best in the world.

Melanie $H$ Wilson Silver, $M A$, is Director of Patient Relations at the Shore Memorial Hospital, New fersey, USA, and is a doctoral candidate at the University of Manchester, England.

\section{References and notes}

1 The bill, A-1843, NJSA 26:2H-12.10 was passed in April 1988. The subsequent regulations empowered by the legislation were titled NJAC 8:43G-4.1 Patient rights; mandatory. From: the New fersey register: the journal of state agency rule making 1989; 21, 15: 21 NJR. 2160-2.

2 By way of explanation for readers unfamiliar with the structure of the American health care system, from a political standpoint, there is no single government provider as there is in England. The system consists of several tiers set within a federal system of government. The following table is a much abridged view of the system from Kovner AJ. Health care delivery in the United States [4th ed]. New York, United States of 
Summary of government's major health care roles

\begin{tabular}{|c|c|c|}
\hline Financing & Delivery & Regulation \\
\hline $\begin{array}{l}\text { Federal } \\
\text { Large role through } \\
\text { Medicare and } \\
\text { Medicaid; other } \\
\text { categorical programs }\end{array}$ & $\begin{array}{l}\text { Operates facilities } \\
\text { for veterans and } \\
\text { Indians }\end{array}$ & $\begin{array}{l}\text { Sets standards for } \\
\text { Medicare } \\
\text { providers; deter- } \\
\text { mines what drugs } \\
\text { and devices may } \\
\text { be sold; prohibits } \\
\text { discriminaton by } \\
\text { providers }\end{array}$ \\
\hline
\end{tabular}

State
Funds Medicaid, Operates mental mental health, medical hospitals, health education and public departments, and health programs

\section{Regulates insur-} ance industry; Licenses facilities and personnel; establishes health codes

Local

Subsidises public hospitals; funds local health departments
Operates county and Establishes local municipal hospitals; health codes operates local health departments
America: Springer Publishing Company, 1990: 300. It should be noted that Medicare is currently under review and expected to be reformed. Begun in 1965, Medicare is the federally funded government programme responsible for providing health care coverage to persons over the age of 65 . In 1972 Medicare was reformed to include the permanently disabled, their dependents, and various others, including those in need of funding for end-stage renal disease. Hence the federal programme to fund the cost of renal dialysis throughout America. The Medicare Program has two parts, part " $A$ ", covering the cost of hospitalisation and some limited home care services and hospice care, and part " $B$ ", which covers some physicians' fees, some out-patient care and some other limited services. The Medicaid Program, also initiated in 1965, was originally intended to provide medical coverage to the indigent poor. The programme is supported by a combination of federal and individual state funding; the latter providing the larger part of funding, as the federal government tries to reduce the federal budget deficit. The Medicaid programmes are designed to be administered by each individual state, with each state determining its own health-related needs and priorities.

3 The author is currently the Director of Patient Relations at a hospital in New Jersey, USA. She has exposure to the practical workings of the New Jersey Patient Bill of Rights on a regular basis. Although each state in America has separate legislation and regulation regarding patient rights, the New Jersey Patient Bill of Rights provides a good example, typically representative of patient rights regulation in the United States.

4 There has been detailed and ongoing monitoring of the National Charter Standards and Local Standards sections of The Patient's Charter document. This has been carried out by individual trusts and health care providers, with the content reported back to the Department of Health, and published in league table documents. This data may be found in the following publication: Department of Health. The patient's charter, hospitals and ambulance services comparative performance guide, 1993-1994. London: Department of Health, 1994. In addition, Community Health Councils monitor and review patient's charter perfof mance and compliance on an ad hoc and individuog. basis. This information has yet to be compiled and analysed nationally. There appears to be no monitorin for compliance or specific research on the patient rights section of The Patient's Charter at this time.

5 Klein R. Looking after consumers in the new NHs British Medical fournal 1990; 300: 1351-2.

6 As a consequence of each state regulating this area dif ferently, it is not possible to compare the Englisfe Patient's Charter and a single general American. document. Therefore, one is compelled to examine an individual state as an example.

7 The wording of the original bill follows with the paw ultimately removed prior to passage in italic "A patient whose rights as defined herein are violated sha have a cause of action against the person committing the violation. The Department of Health may initiate ays action in the name of the State to enforce the provisions of this act and any rules and regulations promulgatedo pursuant to this act. The action may be brought in an court of competent jurisdiction to enforce these rights and to. recover actual and punitive damages for their violation Any plaintiff who prevails in any action shall be entitled recover reasonable attorney's fees and costs of any actio may file a written complaint against a hospital for $\bar{a}$ failure to comply with the provisions of this act, or ans rule or regulation adopted pursuant to the act, eitheev with the hospital or the Department of Health. fore hospital or the Department of Health, as appropriate shall respond promptly in writing to the complain The Department of Health shall investigate a writte complaint filed with the department and report ito findings to the hospital and the patient, and to th appropriate professional board, as deemed appropriat by the Commissioner of Health. The Commissioner of Health may levy a fine against a hospital for a violation of this act, or of any rule or regulation adopted pursuant to this act, in an amount to be determined by the commissioner".

8 New Jersey State Department of Health (1995) NJAC title 8 , ch $43 \mathrm{E}$. All health care facilities enforcement of licensure regulations. Effective date: April 31995.

9 Interview with Mr Robert James Fogg, JD, MPHP Director of Licensure, Certification and Standards, Division of Health Facilities, Evaluation and Licensing New Jersey State Department of Health and Senios Services, 7th July, 1996.

10 Department of Health. Being heard: the report of $\overline{\bar{a}}$. review committee on NHS complaints procedures

London: Department of Health, 1994.
11 HMSO. The patient's charter. London: HMSO, 1995:

12 The New Jersey Patient Bill of Rights, New Jersefy Administrative Code, 8:43G - 4.1 [17].

13 See reference 12:8:43G - 4.1[5].

14 See reference 12: 8:43G - 4.1[8].

15 In Re Quinlan 355 A 2d 647 (NJ, 1976)

16 A TTY is a teletype writer which allows a deaf person to type a message over a telephone line, where a simila machine at the other end can read the message and the recipient can send a written reply. 